\title{
Three Cases of Intentional Ingestion's of Intact Cellular Phones Retrieved from the Gastrointestinal Tract
}

ISSN: 2637-7632

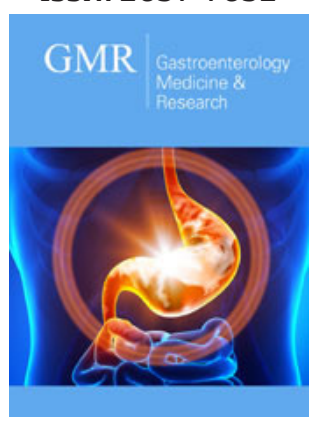

*Corresponding author: Benjamin Koslowsky, Digestive Diseases Institute Shaare Zedek Medical Center 12 Bayit St. Jerusalem 91031, Israel

Submission: 眥 February 24, 2020

Published: 㘹December 16, 2021

Volume 6 - Issue 3

How to cite this article: Evan Avraham Alpert, David Gavriel, Benjamin Koslowsky. Three Cases of Intentional Ingestion's of Intact Cellular Phones Retrieved from the Gastrointestinal Tract. Gastro Med Res. 6(3). GMR. 000640. 2021.

DOI: 10.31031/GMR.2021.06.000640

Copyright@ Benjamin Koslowsky, This article is distributed under the terms of the Creative Commons Attribution 4.0 International License, which permits unrestricted use and redistribution provided that the original author and source are credited.

\author{
Evan Avraham Alpert ${ }^{1}$, David Gavriel ${ }^{2}$ and Benjamin Koslowsky ${ }^{3 *}$ \\ ${ }^{1}$ Department of Emergency, Shaare-Zedek Medical Center, Israel \\ ${ }^{2}$ Department of Surgical, Shaare-Zedek Medical Center, Israel \\ ${ }^{3}$ Digestive Diseases Institute, Shaare-Zedek Medical Center, Israel
}

\section{Introduction}

Gastroenterologists frequently encounter foreign body ingestions. Most accidental ingestions in adults are secondary to impactions of food boluses, primarily meat. Intentional ingestions in adults are usually by patients with psychiatric problems or drug abuse [1]. Foreign bodies can enter the rectum either secondary to ingestion or by direct anal insertion. A few case reports of telephone ingestions have been reported by patients with psychiatric disorders $[2,3]$. We present three cases of prisoners who intentionally swallowed or inserted small cellular telephones. The cell phones were either endoscopically or manually removed. All patients provided consent prior to the phone removal procedure.

Case 1: A 22-year-old male prisoner, presented with a chief complaint of constant abdominal pain and constipation. He admitted to swallowing a small mobile cell phone 4 months prior to his Emergency Department (ED) visit. He was hemodynamically stable. His abdomen was soft with mild tenderness in the left upper quadrant without peritoneal signs. An abdominal radiograph showed a foreign body in the stomach (Figure 1). Endoscopy was performed, and the cell phone was removed using a double snare technique. In this technique, two snares are simultaneously inserted, while one pushes in and the other pulls back, in order to straighten the cell phone. When the cell phone lines up parallel to the endoscope, the scope is the retrieved together with the cell phone (Figure 1). During retrieval, a small tear of the lower esophageal mucosa was noticed, without signs of perforation. His abdomen was soft, and nutrition was renewed uneventfully. He was discharged on omeprazole $40 \mathrm{mg}$ once a day for a month.

Case 2: A 21-year-old male prisoner presented to the ED after having swallowed a mobile cell phone one month prior to the visit. He was brought to be evaluated after the metal detector activated at a security check in the jail. He denied any vomiting, diarrhea, fevers, or chills. His vital signs were stable and physical examination was normal. A chest radiograph was performed that revealed a small mobile cell phone in the stomach (Figure 1). An endoscopy was performed and a $15 \mathrm{x}$ 4-centimeter mobile cell phone was removed from the stomach body by using the double snare technique. The patient was observed for a short period in the ED and then discharged without complications. 

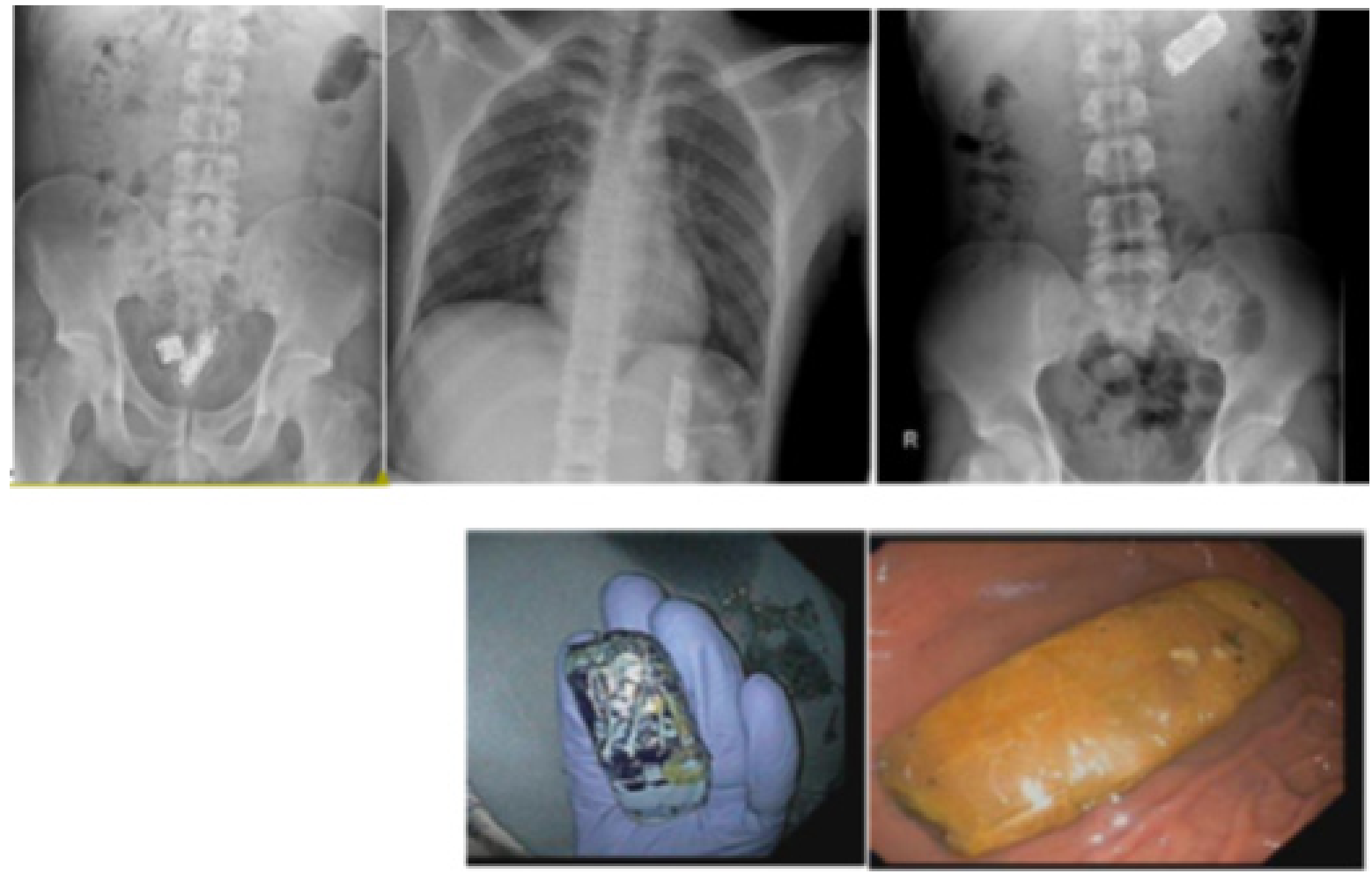

Figure 1: Abdominal radiograms and actual cell phones after retrieved by endoscopy.

Case 3: A 27-year-old male prisoner with a history of past cardiac catheterization, on aspirin, was brought to the ED. The suspicion was raised that he ingested a small cell phone. He was hemodynamically stable. His abdomen was soft and nontender. An abdominal radiograph revealed two foreign bodies in the rectum (Figure 1). A rectal examination was performed that revealed easily movable blunt objects palpated $5 \mathrm{~cm}$ above the anal verge. The patient was put in a left lateral decubitus with knees flexed. Anal lubricating agents were applied to facilitate the procedure. Several attempts to remove the objects with forceps were unsuccessful. They eventually were removed manually, resulting in a minor anal laceration and minimal bleeding that resolved. Due to their size and the fact that they were surrounded by wrapping that was still intact, it was believed that these were inserted via the anus. The patient was observed for 90 minutes, during which time he was asymptomatic, hemodynamically stable, and there was no visible bleeding. He was then discharged from the ED.

\section{Discussion}

While the finding of mobile cell phones in the gastrointestinal tract is rare, these cases demonstrate intentional ingestions or insertions in patients without psychiatric disorders. These cases of small mobile phone ingestions/insertions were done for the purpose of smuggling them into jail. Clearly, an endoscopy is indicated if the device is located in the upper Gastrointestinal (GI) tract. These devices technically don't meet the indications of emergent endoscopy which is usually for objects that are stuck in the esophagus, causing obstructive symptoms, sharp, or disk batteries [4]. Objects in the stomach larger than $2.5 \mathrm{~cm}$ should be endoscopically retrieved but not necessarily urgently. Outpatient retrieval may be an option but is extremely difficult to arrange for prisoners. Additionally, the endoscopy procedure is very complicated as these objects are difficult to grasp and are very large in diameter. A double snare technique uses two snares inserted into the stomach via the endoscope, as the object is grasped by pushing and pulling both snares simultaneously. In that way, the long object can be placed adjacent and parallel to the endoscope. If the objects are located in the rectum, then one must first verify that there are no signs of peritonitis. A rectal examination and determination of sphincter integrity are mandatory. If the objects are not palpable, a sigmoidoscopy should be performed. However, if palpable, manual removal may be attempted in the ED. Occasionally a perianal block or procedural sedation and analgesia will be required [5]. Referral to the surgical team should be made if the objects are sharp or dangerous. Other indications are if ED extraction has been unsuccessful, or if there are signs of perforation or peritonitis [6].

\section{Conclusion}

Intentional cell phone ingestions may be a phenomenon increasingly seen. Endoscopy is indicated for ingestions and a manual retrieval may be attempted for anal insertions. Even many weeks after the ingestion, the cell phones may be intact in the GI tract. A double-snare technique is a safe and easy way for endoscopy retrieval from the stomach. High level of awareness and proper use of technical skills can facilitate a safe retrieval of the foreign bodies. 


\section{References}

1. Sugawa C, Ono H, Taleb M (2014) Endoscopic management of foreign bodies in the upper gastrointestinal tract: A review. World J Gastrointest Endosc 6(10): 475-481.

2. Ali MM, Bahl K, Dross M (2014) Accidental cell phone ingestion with pharyngeal impaction. Del Med J 86(9): 277-279.

3. Levy Z, Jesus J, Osborne A (2013) A man with drug-induced psychosis attempts to swallow his cellular phone. Internal and emergency medicine 8(6): 541-542.
4. Bekkerman M, Sachdev AH, Andrade J (2016) Endoscopic management of foreign bodies in the gastrointestinal tract: A Review of the Literature. Gastroenterology research and practice 2016: 8520767.

5. Cologne KG, Ault GT (2012) Rectal foreign bodies: What is the current standard?. Clinics in colon and rectal surgery 25(4): 214-218.

6. Ostrowski K, Edwards G, Maruno K (2016) Removal of retained rectal foreign bodies in the emergency department. Emergency medicine Australasia: EMA 28(4): 459-461. 